\title{
Effect of Sorafenib on Liver Biochemistry Prior to Vitamin B17 Coadministration in Ehrlich Ascites Carcinoma Mice Model: Preliminary Phase Study
}

\section{Hebatalla M. Nasser 1, *, Sabry Ali El-Naggar ${ }^{2}$, Mohammed El-Sayed Rizk ${ }^{3}$, Alaa Elmetwalli ${ }^{4}$, Afrah Fatthi Salama ${ }^{1}$}

\section{Article history: \\ Accepted : 15/7/2021}

A R T I CLE INFO

Received : 1/7/2021

Available online :
}

${ }^{\mathbf{1}}$ Biochemistry Section, Chemistry Department, Faculty of Science, Tanta University, Egypt

${ }^{2}$ Physiology Department, Faculty of Science, Tanta University, Egypt

${ }^{3}$ Anatomy and Embryology Department, Faculty of Veterinary Medicine, Kafr El-sheikh University, Egypt

${ }^{4}$ Department of Clinical Trial Research Unit and Drug Discovery, Egyptian Liver Research Institute and Hospital, Mansoura, Egypt.

Keywords: Sorafenib, Vitamin B17, Ehrlich Ascites Carcinoma \begin{abstract}
A B S T R A C T
Aim: Background: Voluminous of the anti-tumor drugs in practice known to yield adverse side effects for instance hepatotoxicity. Objective: This preliminary was carried out to ascertain the histological change after treatment with Sorafenib (SOR) before execution the B17 coadministration and detection of the histochemical change in Ascites Carcinoma mice model (EAC). Methods: In total 12 Swiss albino mice received intraperitoneal injections of Sorafenib $(30 \mathrm{mg} / \mathrm{kg}$ mouse) after tumor cells were injected, semi quantifiable scoring of the architectural disparities validated by histopathological inspection of mice tissues. Results: Upsurge of Liver enzymes, Kidney functions and significant reduction after SOR treatment of $\mathrm{Hb}, \mathrm{RBCs}$, and Platelets. Membrane integrity, separation of muscle fiber, Intrusion of inflammatory cells, Edematous intramuscular space were evaluated in addition, liver tissue revealed large focal area and diffuse pleomorphic darkly basophilic cells in the perivascular area around the dilated central vein $(\mathrm{CV})$ besides the mild dilation of some blood sinusoids. Improvement in the histological pictures of hepatic tissues in comparison to EAC bearing positive control group were enhanced Conclusion: Sorafenib showed alterations in histological mice tissues, however improvements in biochemical parameters were noted; that's why the Coadministration of B17 will be applied to alleviate the side effects of Sorafenib on the next perspective study.
\end{abstract}

C) 2021Publisher All rights reserved.

\section{INTRODUCTION}

Cancer is a type of diseases or ailments categorized by an unrestrained cell division and the aptitude of the cells to blowout, whichever by straight growth into together tissue via invasion or by embedding into reserved sites by metastasis where cancer cells are ecstatic

Corresponding author: Hebatalla M. Nasser, Biochemistry Division, Chemistry Department, Faculty of science, Tanta University, Egypt 
over the bloodstream or lymphatic system [1]. Ehrlich ascites carcinoma (EAC) is one of the investigational tumors imitative from spontaneous mouse adenocarcinoma [2], [3]. Approximating to other tumors emerging in body cavities, EAC cells block up the peritoneal cavity by fast division of cells, accrual of a fluid named ascitic fluid, and the animal dies 17-18 days subsequent EAC transplantation [4], [5]. A confined inflammatory reaction was confirmed after the Ehrlich ascitic tumor grafting [6], with cumulative vascular penetrability which outcomes in a strong edema materialization, migration of cells, advanced ascitic fluid creation which is crucial for tumor evolution since it creates a nonstop nutritive cradle for tumor cells [7],[8].

SOR is an oral multi-kinase inhibitor utilizing its properties via RAF/MEK/ERK pathway [9], vascular endothelial growth factor receptor (VEGFR), and plateletderived growth factor receptor beta (PDGFR- $\beta$ ) tyrosine kinases [10]. A prolong overall survival in patients with advanced liver cancer could be due to sorafenib administration. However, there is a theories concluded that the side effects on liver histology after Sorafenib administration may be arose [11], [12]. Consequently, this rationale of our work aims to pattern the possible effect of Sorafenib on Liver tissue in EAC mice model prior to B17 coadministration in EAC mice model.

\section{MATERIALS AND METJODS: \\ 2.1 Chemicals and materials}

Sorafenib was purchased from BAYER Company. Ehrlich ascites carcinoma (EAC) was conquered from the Cancer Biology Unit (CBU), Al-Kaser AlEini, Egypt which maintained and propagated by serial transplantation (i.p) in an aseptic environment.

\subsection{Experimental animals}

The experiment was carried out on 12 female mice weigh up 20- $25 \mathrm{~g}$ and of 10-12 weeks ages in addition to control group $(n=6)$. Mice were maintained under standardized conditions. The Mice were kept in a controlled temperature environment with a $24 \mathrm{~h}$ cycle. All mice were adapted to the place for two weeks before the starting of the experiment. The animals were nourished with a normal water ad libtium and diet during the period of the experiment. The investigational procedure was ratified by Confined Ethics Committee and Animals Research, Tanta University (2019).

\subsection{Experimental design}

Twelve mice were inoculated with EAC-cells and then divided into 2 groups (Gp, n=6) as following: Gp1: (EACbearing positive control group): mice inoculated with tumor cells alone, Mice were injected with EAC cells $(300 \mu \mathrm{l}$ of $1.0 \times 106$ cells /mouse (i.p.) on the day "0". Gp2: (EAC+ Sorafenib IP): mice were inoculated with EAC and then treated with Sorafenib (IP) daily for 14 days. The control group $(n=6)$ remains plateau and considered to be the baseline comparison.

\subsection{Biochemical parameters determination}

Serum ALT and AST activities and albumin were measured spectrophotometrically using kinetic method according to IFCC; International Federation of Clinical Chemistry [13].

\subsection{Hematological assay}

Automated hematology analyzer KX-21N Sysmex ${ }^{\circledR}$ instrument was used for the assay of hemoglobin $(\mathrm{Hb})$ content, count of blood cells, and platelets count

\subsection{Histo-pathological analysis of liver tissues}

The fixation of Liver tissues were precisely embedded in formalin solution $(10 \%)$, then were dried up in arising sequences of ethanol, afterthought xylene was applied for ethanol clearance, and lastly implanted in paraffin wax. Liver tissue were partitioned at 5-7 $\mu \mathrm{m}$ by microtome and were discolored with eosin and Hematoxylin, formerly the stained sections were scrutinized and were 
snapped under a light microscope to detect histo-pathological changes [14]

\section{Results}

\subsection{Effect of SOR on liver biochemical test}

The obtained data confirmed that serum ALT activity in EAC group was significantly upsurge compared to the control group. In EAC+SOR IP group there was no improvement as compared with control group with mean difference (4 ) which mean that the level of ALT remain high above normal range. However, the levels of liver enzymes were significantly improved if compared with EAC positive control group. Similarly, albumin was reduced in both groups, but still with lower value if compared with control group as publicized in Table (1).

\subsection{Hematological outcomes after SOR} administration

Cancer-bearing mice disclosed a significant lessening in Red Blood cell (RBCs) count $\left(7.37 \pm 0.26 \times \mathrm{I}^{\wedge}{ }^{6}\right.$ cells $\left./ \mu \mathrm{l}\right)$ and the level of Hemoglobin $(\mathrm{Hb})$ $(10.05 \pm 0.36 \mathrm{~g} / \mathrm{dl})$ with significant P-value (0.001) and (0.0001) respectively. Animals that received SOR IP only and those who received AMY+SOR oral showed moderate significant differences in the levels of $\mathrm{Hb}$ as compared to the normal control group $(\mathrm{P}<0.01)$; by comparison to the normal control group, RBCs count did not show any differences. However, treatment with SOR IP did not show any significance if paralleled with the control group as per Platelets counts as shown in Table (2).

\subsection{Histo-pathological examination in EAC mice model}

In normal control group, the histopathological examination showed normal hepatic architecture; central vein (CV), portal vein area (PV), polyhedral-shaped hepatocytes, and blood sinusoids as shown in Figure (1-A). However, in EAC bearing mice showed aggregations of pleomorphic, hyper chromatic, and darkly basophilic cells in the perivascular area around the dilated and congested central vein (CV) and severe hepatocellular necrosis as publicized in Figure (1-B) and Figure (1C).

$\mathrm{EAC}+$ Sorafenib (IP) group showed large focal area and diffuse pleomorphic darkly basophilic cells (arrows) in the perivascular area around the dilated central vein $(\mathrm{CV})$ besides the mild dilation of some blood sinusoids as presented in Figure (1-D).

On the subject of semi-quantifiable scoring of the architectural disparities validated by histo-pathological inspection of mice model liver tissues, the histopathological exploration bared a mild diminished degree of inflammatory cellular cue and comparatively altered the membrane integrity as compared with EAC. Mice in the baseline group disclosed no alterations in the histo-architecture of the liver sections as shown in Table (3).

\section{Discussion}

According to the European Union and the United States, the multi-kinase inhibitor SOR was newly ratified for the dealing of HCC, and may be jumble-sale in a cumulative number of countries [15], [16]. Though treatment with Sorafenib may be operational in patients with unconventional $\mathrm{HCC}$, petite treatment is notorious roughly with its liver-specific fibrosis or on liver histology [17].

Severe side effects may upsurge or even to be exclude therapy with Sorafenib [18], [19]. Tumor-independent remunerations cannot be omitted in SORtreated patients [20]. Contemporary studies in mice models of the liver tissues signposted that SOR amends portal hypertension of cirrhotic mice via a diminution in intrahepatic vascular confrontation [21], [20]. At this point, we validate that the treatment with SOR lessens a mild intrahepatic sinusoidal vascular remodeling in mice with conventional liver tissues. In addition, decreased degree of inflammatory cell 
infiltration and comparatively altered the membrane integrity as compared with EAC could be arise.

EAC is a transplantable, ailing discriminated malicious tumor and one of the experimental breast tumor-derived from spontaneous mouse adeno-carcinoma [22]. Related to other tumors developing in body cavities, EAC cells plug the peritoneal cavity by rapid separation of cells, buildup of a fluid baptized tumor ascitic fluid, and the animal dies 17-18 days following EAC transplantation [23].

It is known that hepatocytes are the main target for hepatic enzyme metabolism. It was itemized that Ehrlich carcinoma persuaded an upsurge in MDA level that was related to compromise hepatic function, as evidenced by increased serum activities of AST and ALT. The level of liver enzymes augmented in serum of EAC - bearing mice signifying overall-toxicity [24]. Dolai et al. [25] publicized that EAC mice revealed upraised activities of liver enzymes such as SGOT, SGPT, attributable to hepatocellular damages.

Another possible explanation for the increased levels of AST and ALT is escape-mechanism of all hepatic-enzymes from the neoplastic cells into blood or may be down to the discharge of enzymes from normal tissue attacked by tumor or may be because of the conceivable effect of the tumor on distant tissue leading to the defeat of its enzyme and discharge into the blood [26]. This may be true in this study also. In hepatic dysfunction, decrease levels in serum albumin was also observed in previous studies such as Aldubayan et al. [27] and Mutar et al. [26]. A hale and energetic liver is so essential for metabolism of proteins from the time when the liver disease is habitually allied with shifts in proteins and turbulences of protein breakdown [29].

The EAC-behavior mice revealed a diminution in $\mathrm{Hb}$ and $\mathrm{RBC}$ count. This may be due to disproportionate hemolysis and iron deficiency [30]. SOR administration slightly lessen the $\mathrm{Hb}$ and RBCs count of tumor-bearing animals. SOR might has a partial response to the synthesis of hemoglobin or prevented hemolysis in specific cases [31]. Our results thus suggested that the SOR is involved in low grade of anemia and RBCs count. This could be explained by the dual etiology of SOR and EAC in lessening the $\mathrm{Hgb}$ and $\mathrm{RBCs}$ [30]. The existing study signified that the SOR administration slightly returned the platelets counts to be afar from the level of the baseline. However, this is concordant with the Abou-Alfa et al. [32] who concluded that the association between platelet count and outcome of patients with SOR is inconsistent and still controversial.

In line with our histo-pathological studies, tissues of the liver of EAC animals discolored with eosin and hematoxylin publicized aggregations of pleomorphic, hyper chromatic, and darkly basophilic cells in the perivascular area around the dilated and congested central vein and hepatocellular necrosis. Additionally, the worsening changes such as loss of histoarchitecture, by reason of microvascular fatty fluctuations and materialization of hepatocytes with pleomorphic condensed nuclei.

Since the EAC-bearing mice showed various histo-pathological alternations including an increased number of necrotic hepatocytes with mild dilation of blood sinusoids, mild degeneration of hepatocytes, and mild Kupffer cells activity [33]. It was also conveyed that the incidence of tumors in the human body of experimental animals is recognized to mark numerous tasks of the vital organs particularly the liver, even when the tumor site doesn't hinder unswervingly with organ functions [34],[35].

\section{References}

[1] M. Pinter, M. Trauner, M. PeckRadosavljevic, and W. Sieghart, "Cancer and liver cirrhosis: implications on 
prognosis and management," ESMO open, vol. 1, no. 2, p. e000042, 2016.

[2] M. Ozaslan, I. D. Karagoz, I. H. Kilic, and M. E. Guldur, "Ehrlich ascites carcinoma," African J. Biotechnol., vol. 10, no. 13, pp. 2375-2378, 2011.

[3] M. A. Mansour, A. F. Salama, W. M. Ibrahim, and E. S. Shalaan, "Assessment of Autophagy as Possible Mechanism of the Antitumor Effects of Arsenic Trioxide and/or Cisplatin on Ehrlich Ascites Carcinoma Model.," Alexandria J. Vet. Sci., vol. 61, no. 1, pp. 159-167, 2019.

[4] F. Islam, H. Khatun, S. Ghosh, M. M. Ali, and J. A. Khanam, "Bioassay of Eucalyptus extracts for anticancer activity against Ehrlich ascites carcinoma (eac) cells in Swiss albino mice," Asian Pac. J. Trop. Biomed., vol. 2, no. 5, pp. 394-398, 2012.

[5] R. Abu-Khudir, A. F. Salama, W. M. Ibrahim, and M. E. Shams, "Ameliorative Effect of Trehalose on Liver Due to Doxorubicin-Induced Cardiomyopathy in Mice.," Alexandria J. Vet. Sci., vol. 63, no. 1, 2019.

[6] M. K. Elsisy, W. M. Ibrahim, A. F. Salama, and S. M. Kasem, "The Antitumor Potential of Quercetin on Solid Ehrlich Tumor in Female Mice. J Can Sci Res 2: 108," of, vol. 7, p. 3, 2017.

[7] T. F. Mutar, E. Tousson, E. Hafez, M. Abo Gazia, and S. B. Salem, "Ameliorative effects of vitamin B17 on the kidney against Ehrlich ascites carcinoma induced renal toxicity in mice," Environ. Toxicol., vol. 35, no. 4, pp. 528537, 2020.

[8] E. S. Shalaan, A. F. Salama, W. M. Ibrahim, and M. A. Mansour, "Biochemical studies of the effect of arsenic trioxide on Ehrlich ascites tumor: Thesis Abstract," Int. J. Cancer Biomed. Res., vol. 5, p. 26, 2021.

[9] S. Gahr, T. Wissniowski, S. Zopf, D. Strobel, A. Pustowka, and M. Ocker, "Combination of the deacetylase inhibitor panobinostat and the multi-kinase inhibitor sorafenib for the treatment of metastatic hepatocellular carcinoma-review of the underlying molecular mechanisms and first case report," J. Cancer, vol. 3, p. 158, 2012.

[10] J. A. Gollob, S. Wilhelm, C. Carter, and S. L. Kelley, "Role of Raf kinase in cancer: therapeutic potential of targeting the Raf/MEK/ERK signal transduction pathway," in Seminars in oncology, 2006, vol. 33, no. 4, pp. 392406.

[11] R. Ma et al., "Sorafenib: A potential therapeutic drug for hepatic fibrosis and its outcomes," Biomed. Pharmacother., vol. 88, pp. 459-468, 2017.

[12] M. Hennenberg et al., "Hepatic and HSC-specific sorafenib effects in rats with established secondary biliary cirrhosis," Lab. Investig., vol. 91, no. 2, pp. 241-251, 2011.

[13] H. U. Bergmeyer, "Methods of enzymatic analysis vol. XII: drugs and pesticides." VCH, Weinheim, FRG, 1986.

[14] R. A. Drury and E. A. Wellington, "Carlton's Histo-pathological Techniques: Oxford University press." Oxford, London, New York, 1976.

[15] J. M. Llovet et al., "Sorafenib in advanced hepatocellular carcinoma," $N$. Engl. J. Med., vol. 359, no. 4, pp. 378390, 2008.

[16] A. X. Zhu and J. W. Clark, "Commentary: Sorafenib Use in Patients with Advanced Hepatocellular Carcinoma and Underlying Child-Pugh B CirrhosisEvidence and Controversy," Oncologist, vol. 14, no. 1, pp. 67-69, 2009.

[17] M. Pinter et al., "Sorafenib in unresectable hepatocellular carcinoma from mild to advanced stage liver cirrhosis," Oncologist, vol. 14, no. 1, pp. 70-76, 2009.

[18] C. Schramm, G. Schuch, and A. W. Lohse, "Sorafenib-induced liver failure," Am. J. Gastroenterol., vol. 103, no. 8, p. 2162, 2008.

[19] L. Llanos, P. Bellot, P. Zapater, M. Pérez-Mateo, and J. Such, "Acute hepatitis in a patient with cirrhosis and 
hepatocellular carcinoma treated with sorafenib," Am. J. Gastroenterol., vol. 104, no. 1, p. 257, 2009.

[20] T. Yau et al., "Phase 2 open-label study of single-agent sorafenib in treating advanced hepatocellular carcinoma in a hepatitis B-endemic Asian population: Presence of lung metastasis predicts poor response," Cancer, vol. 115, no. 2, pp. 428-436, 2009.

[21] M. Mejias, E. Garcia-Pras, C. Tiani, R. Miquel, J. Bosch, and M. Fernandez, "Beneficial effects of sorafenib on splanchnic, intrahepatic, and portocollateral circulations in portal hypertensive and cirrhotic rats," Hepatology, vol. 49, no. 4, pp. 1245-1256, 2009.

[22] E. Tousson, E. Hafez, M. M. A. Gazia, S. B. Salem, and T. F. Mutar, "Hepatic ameliorative role of vitamin B17 against Ehrlich ascites carcinoma-induced liver toxicity," Environ. Sci. Pollut. Res., vol. 27, no. 9, pp. 9236-9246, 2020.

[23] O. R. Abou Zaid, M. R. Hassanein, Y. A. EL-Senosi, and M. F. EL-Shiekha, "Biochemical effect of some antioxidant on metabolic changes in experimentally induced tumor in female mice," Benha Vet. Med. J., vol. 1, no. 1, pp. 52-60, 2011.

[24] A. Bhattacharyya et al., "Black teainduced amelioration of hepatic oxidative stress through antioxidative activity in EAC-bearing mice," J. Environ. Pathol. Toxicol. Oncol., vol. 26, no. 4, 2007.

[25] N. Dolai, I. Karmakar, R. B. S. Kumar, B. Kar, A. Bala, and P. K. Haldar, "Evaluation of antitumor activity and in vivo antioxidant status of Anthocephalus cadamba on Ehrlich ascites carcinoma treated mice," J. Ethnopharmacol., vol. 142, no. 3, pp. 865-870, 2012.

[26] S. A. Center, "Interpretation of liver enzymes," Vet. Clin. North Am. Small Anim. Pract., vol. 37, no. 2, pp. 297-333, 2007.

[27] M. A. Aldubayan, R. M. Elgharabawy, A. S. Ahmed, and E. Tousson, "Antineoplastic activity and curative role of avenanthramides against the growth of ehrlich solid tumors in mice," Oxid. Med. Cell. Longev., vol. 2019, 2019.

[28] T. F. Mutar, M. A. Gazia, S. B. Salem, E. H. Hammed, and E. Tousson, "Ehrlich ascites carcinoma bearing mice as model of human hepatocellular carcinoma," Asian J. Res. Reports Hepatol., pp. 1-9, 2019.

[29] A. Lawan and A. M. Bennett, "Mitogen-activated protein kinase regulation in hepatic metabolism," Trends Endocrinol. Metab., vol. 28, no. 12, pp. 868-878, 2017.

[30] S. Sannigrahi, U. K. Mazumder, D. Pal, and S. L. Mishra, "Terpenoids of methanol extract of Clerodendrum infortunatum exhibit anticancer activity against Ehrlich's ascites carcinoma (EAC) in mice," Pharm. Biol., vol. 50, no. 3, pp. 304-309, 2012.

[31] F. Pitoia, E. Abelleira, F. Jerkovich, C. Urciuoli, and G. Cross, "Partial response to sorafenib treatment associated with transient grade 3 thrombocytopenia in a patient with locally advanced thyroid cancer," Arch. Endocrinol. Metab., vol. 59, no. 4, pp. 347-350, 2015.

[32] G. K. Abou-Alfa et al., "Platelet count at baseline (Plt) and outcomes in patients (pts) with advanced hepatocellular carcinoma (HCC) treated with sorafenib (S) in CALGB80802 (Alliance)(C8)." American Society of Clinical Oncology, 2018.

[33] S. K. Nasr Eldeen, W. M. Ibrahim, A. Salama, M. Elghannam, and A. Khamis, "Evaluation of the antitumor effect of trehalose in experimental models: $\mathrm{PhD}$ Thesis Abstract," Int. J. Cancer Biomed. Res., 2021.

[34] D. Ashokkumar, U. K. Mazumder, M. Gupta, and V. T. Selvan, "Effect on inhibition of proliferation and antioxidant enzyme level of Lippia nodiflora in EAC cell line treated mice," J. Complement. Integr. Med., vol. 6, no. 1, 2009. 
[35] M. Gupta, U. K. Mazumder, R. S. Kumar, T. Sivakumar, and M. L. M. Vamsi, "Antitumor activity and antioxidant status of Caesalpinia bonducella against Ehrlich ascites carcinoma in Swiss albino mice," $J$. Pharmacol. Sci., vol. 94, no. 2, pp. 177184, 2004.

Table1: Serum parameters ALT (U/L), AST (U/L), and Albumin (g/dL) in different groups

\begin{tabular}{|c|c|c|c|}
\hline $\begin{array}{c}\text { Group } \\
(\text { Mean } \pm \text { SEM })\end{array}$ & ALT (U/L) & $\begin{array}{l}\mathbf{A S T} \\
(\mathbf{U} / \mathrm{L})\end{array}$ & $\begin{array}{l}\text { Albumin } \\
\text { (g/dl) }\end{array}$ \\
\hline Control & $44.75 \pm 1.25^{\mathrm{a}}$ & $72.50 \pm 14.87^{\mathrm{a}}$ & $4.3 \pm 0.08^{\mathrm{a}}$ \\
\hline EAC & $86.50 \pm 7.51^{\mathbf{a}, \mathbf{b}, \mathbf{c}}$ & $265.0 \pm 14.72^{\mathbf{a}, \mathbf{b}, \mathbf{c}}$ & $2.35 \pm 0.09^{\mathbf{a}, \mathbf{b}, \mathbf{c}}$ \\
\hline EAC + SOR IP & $50.00 \pm 1.58^{\mathbf{a}, \mathbf{b}, \mathbf{c}}$ & $74.00 \pm 3.80^{\mathbf{a}, \mathbf{b}, \mathbf{c}}$ & $3.2 \pm 0.11^{\mathbf{a}, \mathrm{b}}$ \\
\hline
\end{tabular}

Table (2): Hematological parameters of control and different mice groups

\begin{tabular}{|c|c|c|c|}
\hline $\begin{array}{l}\text { Parameters } \\
\text { Group }\end{array}$ & $\begin{array}{l}\text { Hb } \\
(\mathrm{g} / \mathrm{dL}) \\
(\text { Mean } \pm \text { SEM })\end{array}$ & $\begin{array}{l}\text { RBCs } \\
\left(\times 10^{6} / \mu \mathrm{l}\right) \\
(\text { Mean } \pm \text { SEM })\end{array}$ & $\begin{array}{l}\text { Platelets } \\
\left(\times 10^{3} / \mu \mathrm{l}\right) \\
(\text { Mean } \pm \text { SEM })\end{array}$ \\
\hline Control & $12.13 \pm 0.14^{a}$ & $9.25 \pm 0.27^{\mathrm{a}}$ & $623.0 \pm 4.06^{a}$ \\
\hline EAC & $10.05 \pm 0.36^{\mathrm{a}, \mathrm{b}, \mathrm{c}}$ & $7.37 \pm 0.26^{a, b}$ & $669.0 \pm 10.06^{a, b}$ \\
\hline EAC + SOR IP & $9.30 \pm 0.21^{\mathrm{a}}$ & $6.72 \pm 0.31^{\mathrm{a}}$ & $442.3 \pm 9.54^{\mathrm{a}, \mathrm{b}, \mathrm{c}}$ \\
\hline
\end{tabular}


Table (3): Semi quantifiable scoring of the architectural disparities validated by histo-pathological inspection of mice liver tissues.

\begin{tabular}{lccc}
\multicolumn{1}{c}{ Parameters/ Score } & Control & EAC & EAC+SOR (IP) \\
\hline Membrane integrity & - & +++ & +++ \\
Separation of muscle & -++ & ++ \\
fiber & - & +++ & \\
Infiltration of & & & ++ \\
inflammatory cells & - & +++ & ++ \\
\hline Basophilic cells & & & \\
\hline
\end{tabular}

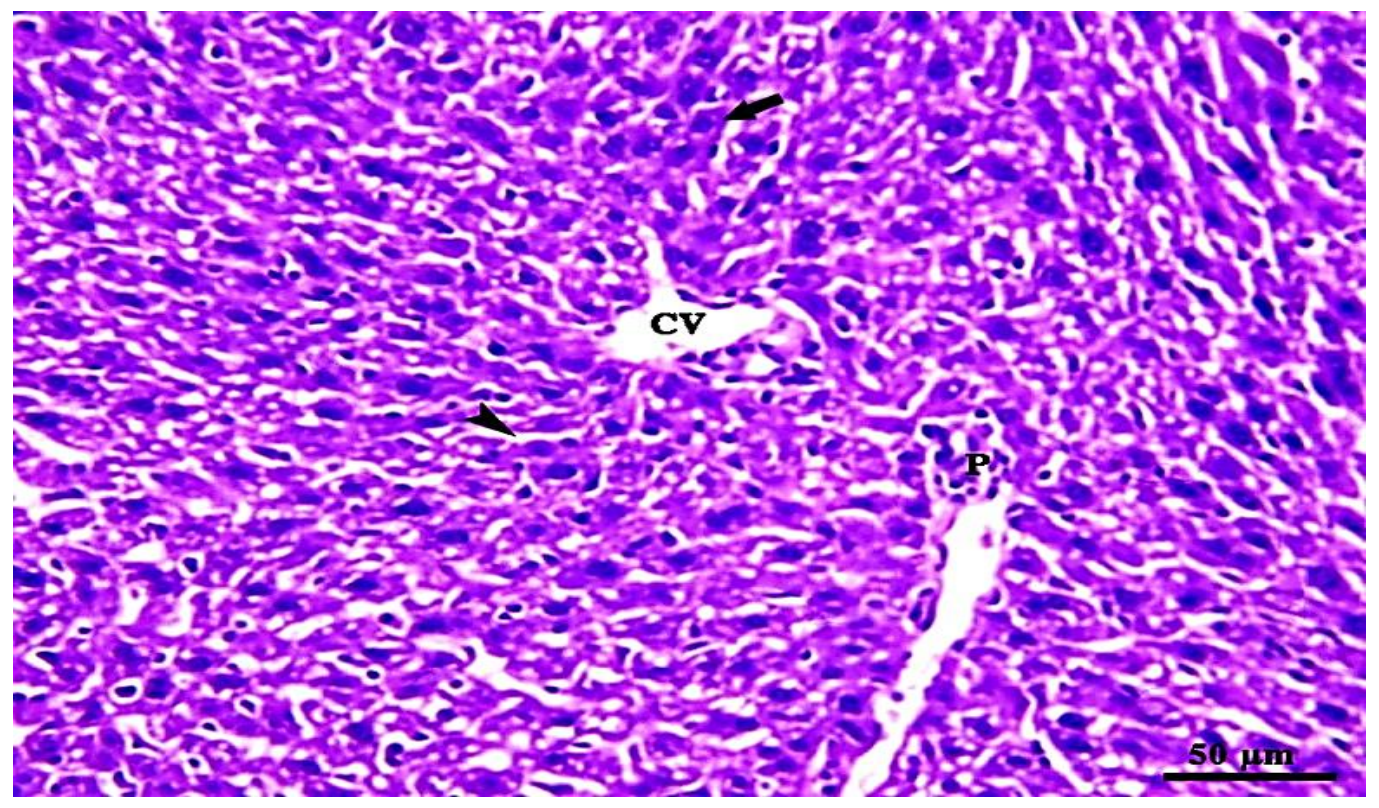

Figure 1a: Photomicrograph of liver of control group viewing standard hepatic manner; central vein $(\mathrm{CV})$, portal area $(\mathrm{P})$, polyhedral-shaped hepatocytes (arrow) and blood sinusoids (arrow head). 


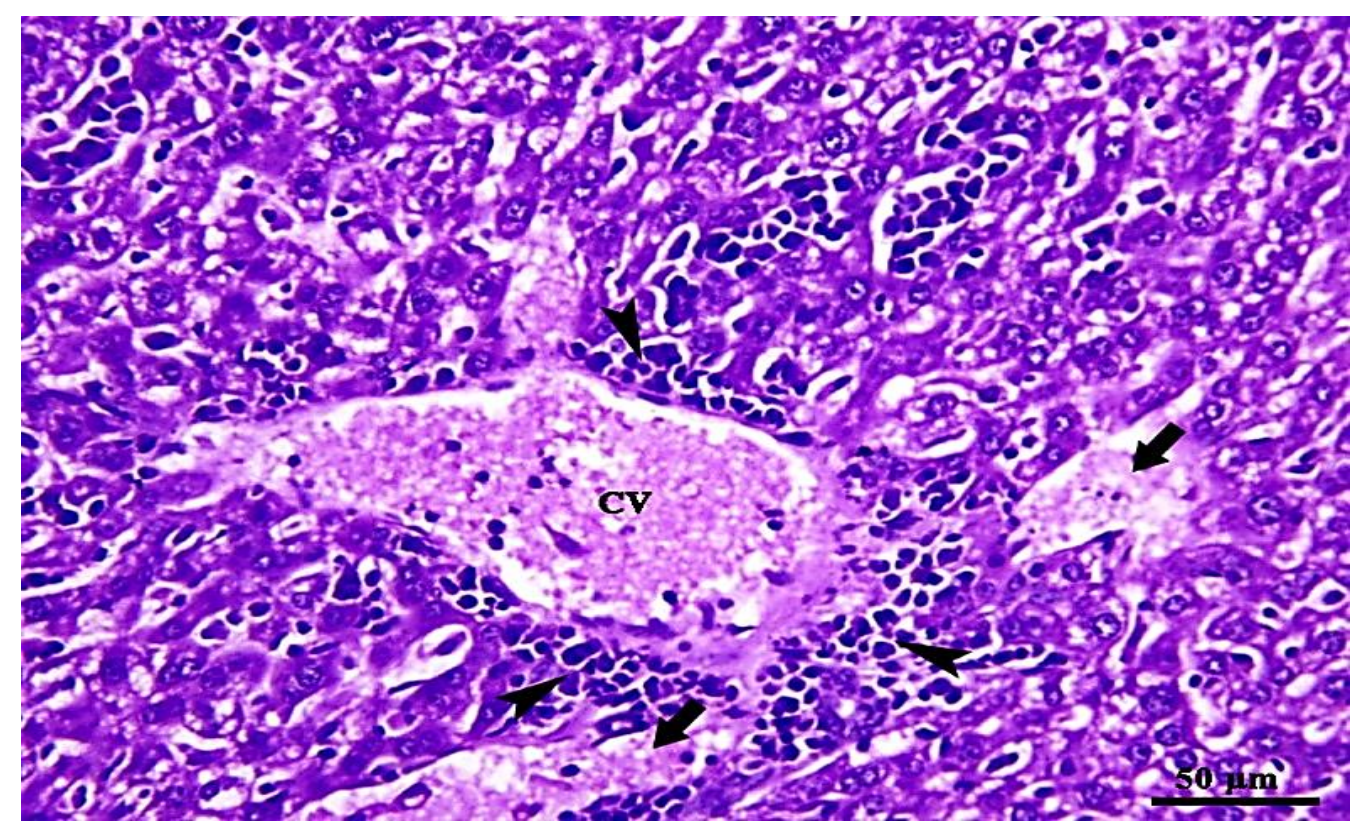

Figure 1-B: Photomicrograph of liver of EAC group showing aggregations of pleomorphic, hyper chromatic, and darkly basophilic cells (arrow heads) in the perivascular area around the dilated and congested central vein (CV). Hepatocellular necrosis (arrows).

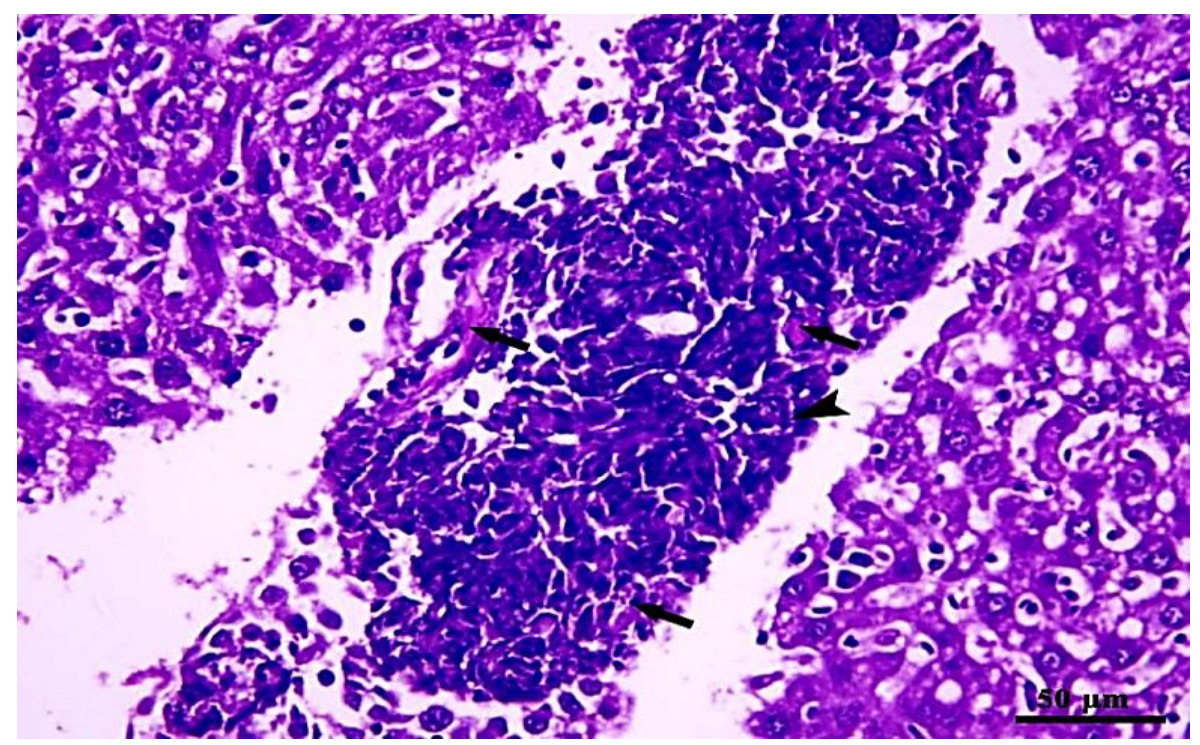

Figure 1-C: Photomicrograph of liver of EAC group showing aggregation of pleomorphic, hyper chromatic and darkly basophilic cells (arrow heads) with severe hepatocellular necrosis (arrows). 


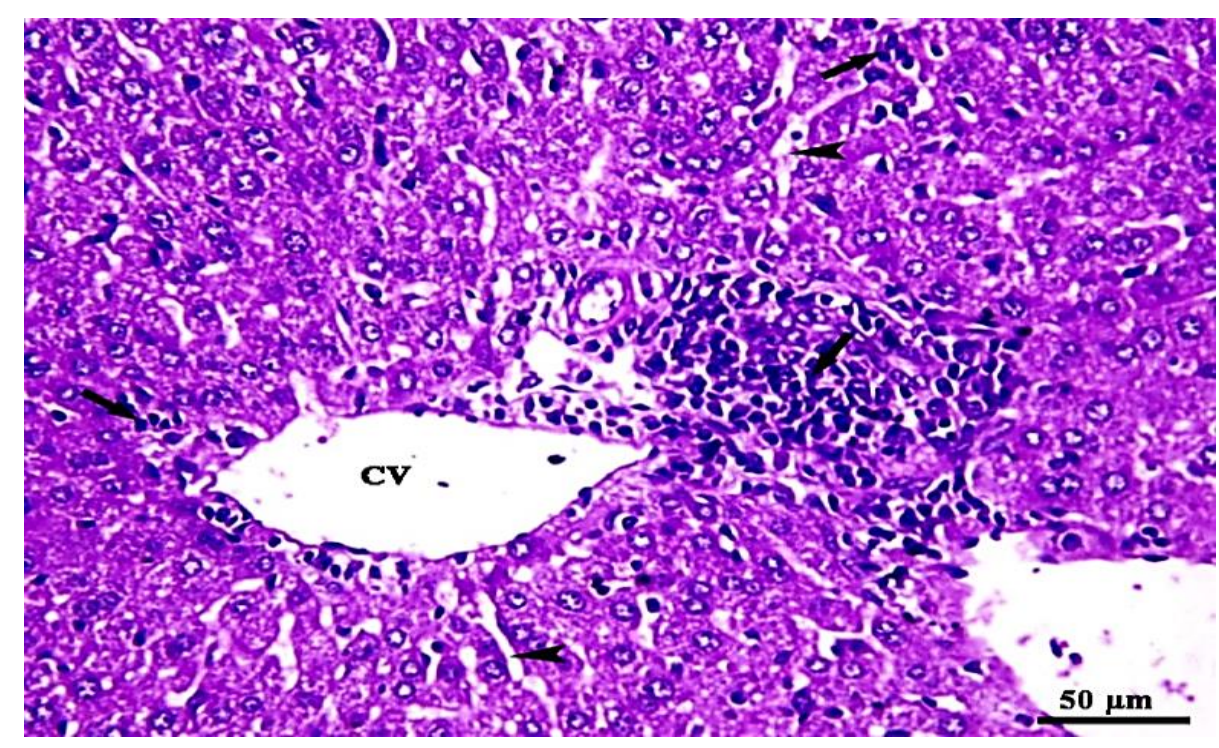

Figure 1-D: Photomicrograph of liver of EAC + Sorafenib (IP) group showing large focal area and diffuse pleomorphic darkly basophilic cells (arrows) in the perivascular area around the dilated central vein (CV) besides the mild dilation of some blood sinusoids (arrow heads). 